УДК: [618.3-06:616.379-008.64-053.1]-073.432.19

\section{И.Н. Сафонова}

Харьковская медицинская академия последипломного образования МЗ Украины (г. Харьков, Украина)

\author{
ВОЗМОЖНОСТИ АНТЕНАТАЛЬНЫХ \\ ЭХОГРАФИЧЕСКИХ МОНИТОРИНГОВ \\ ПРИ САХАРНОМ ДИАБЕТЕ БЕРЕМЕННЫХ \\ В ДИАГНОСТИКЕ ДИАБЕТИЧЕСКОЙ \\ ФЕТОПАТИИ И ОПРЕДЕЛЕНИИ СТЕПЕНИ \\ ПЕРИНАТАЛЬНОГО РИСКА
}

\title{
Резюме.
}

Цель работы - изучение возможностей антенатальных ультразвуковых (УЗ) мониторингов в диагностике диабетической фетопатии и определении степени перинатального риска при сахарном диабете (СД) беременных.

Материал и методы. Проспективное когортное обсервачионное одноцентровое исследование. Эхографически обследованы 120 беременных женщин с СД: 3(2,5\%) - с неконтролируемой гликемией, $31(25,8 \%)$ - с субоптимально контролируемой гликемией, 89 (74,1\%) - с хорочим гликемическим контролем. Исследования до рождения включали визуальную оиенку анатомии плода, стандартную фетометрию, измерение длины печени, размеров сердияа плода, толщины подкожного буккального жира и жирового слоя туловища плода (передней брюшной стенки и над лопаткой), сравнение звукопроводимости легких и печени плода, оиенку индекса амниотической жидкости. Проводилась допплерография артерии пуповины (АП), маточных артерий (МА), фетальной средней мозговой артерии (СМА). Постнатальные результаты классифицировались как неблагоприятный общций постнатальный результат, ОПР (перинатальная или младенческая смерть, метаболический ацидоз при рождении, оиенка 0-4 баллов по шкале Апгар) и неблагоприятный клинический постнатальный результат, КПР (персистирующая постнатальная заболеваемость).

Результаты. У 3/120 (2,5\%) плодов встречались структурные аномалии (эмбриопатии). Синдром диабетической фетопатии имелся у 17/120 (14\%) новорожденных. Общее число плодов и новорожденных с неблагоприятными ОПР и КПР составило 19/120 (15,8\%): неблагоприятные ОПР имели 8/120 (6,6\%), неблагоприятные КПР-11/120 $(9,1 \%)$ плодов. Антенатальные факторы, имевшие наибольшее значение для предсказания диабетической фетопатии при рождении: субоптимально контролируемая гликемия (RR 6,0, 4,8-8,32 nри CI 95\%), двойной контур головки плода (подкожный отек) 5+мм (RR 3,34, 3,79-5,91 при CI 95\%), гипертрофическая MKП (RR 4,0, 3,175,43 при CI 95\%), толщчина n/к жира туловища плода 5+мм (RR 2,65, 1,90-3,6 при CI 95\%). Толщина инсулинчувствительного подкожного жирового слоя туловища плода была более надежным предиктором фетопатии, чем предполагаемая симметричная либо асимметричная макросомия.

Cильные связи с неблагоприятными ОПР (RR 9,53-2,9 при 95\% CI) демонстрировали такие антенатальные предикторы, как неконтролируемая и субоптимально контролируемая гликемия, задержка роста плода, допплеровские изменения АП и СМА. То есть эхографические признаки плацентарной дисфункиии при СД (ЗРП и допплеровские изменения АП и/или СМА) были важными и универсальными предикторами высокого перинатального риска и неблагоприятного результата беременности, хотя при этом не являлись предикторами собственно диабетической фетопатии. Высокорезистентный кровоток АП и МА, а также хорошо контролируемая гликемия не имели диагностического и прогностического значения (RR 0,04-1,96 при CI 95\%) для предсказания неблагоприятных ОПР при материнском CД. RR развития РДС после рождения при различных антенатальных эхографических и допплеровских особенностях находился в диапазоне от 0,5 до 1,46 при 95\% CI.

Выводы. Результаты антенатальных УЗ мониторингов при СД строго зависят от типа гликемического контроля. Антенатальные эхографические мониторинги эффективны в диагностике диабетической фетопатии и предсказании перинатального результата, но неэффективны в прогнозировании функииональной зрелости легких и развития РДС у новорожденных от матерей с СД.

Ключевые слова: беременность, сахарный диабет, ультразвуковой мониторинг, диабетическая фетопатия, перинатальный результат.

\section{Введение}

Сахарный диабет (СД) - это обобщенное название группы заболеваний, для которых характерны хроническая гипергликемия, обусловленная абсолютной или относительной инсулиновой недостаточностью, вследствие чего нарушаются все виды метаболизма, поражаются сосуды (ангиопатия), нервы (нейропатии) и другие органы и ткани [1].

Согласно классификации ВО3 (1999), различают следующие виды заболевания: СД 1-го типа (“инсулинозависимый” по более ранним классификациям); СД 2-го типа (“инсулинонезависимый”); гестационный или диабет беременных; вторичный СД, вызванный другой причиной (болезнью).

Диабет, имевший место у женщины до наступле- ния беременности, называют передгестационным. Гестационный диабет возникает непосредственно во время беременности и проходит после ее окончания. У беременных женщин чаще встречается передгестационный диабет 1-го и 2-го типа и гестационный СД, тогда как вторичный СД развивается гораздо реже. В Украине среди беременных с передгестационным диабетом значительно преобладают больные СД 1 типа [1].

Диабет - перинатально значимая экстрагенитальная патология, повышающая риск преэклампсии, преждевременных родов, мертворождения, пороков развития плода, многоводия [2]. Негативное воздействие СД на формирование и развитие плода может проявляться в виде 
эмбриопатии, макросомии, диабетической кардиомиопатии, гепатомегалии, неонатальной гипогликемии, функциональной незрелости, а также приводить к преждевременным родам и антенатальной гибели (в том числе необъяснимой, у хорошо компенсированных пациенток) [3].

Диабетическая фетопатия - фактор риска перинатальной заболеваемости и смертности, комплекс патологических изменений в организме плода. Фетопатия может являться причиной акушерских осложнений, родового травматизма, респираторного дистресс-синдрома (РДС) [4], a также гипогликемии новорожденных и других постнатальных осложнений [5]. С другой стороны, сама беременность отрицательно влияет на течение СД, способствуя прогрессированию нефропатии у матери [2]. Проблема СД при беременности настолько актуальна, что ей посвящаются специальные акушерские и перинатальные форумы. Ведение беременности при СД требует мультидисциплинарного подхода и индивидуальной тактики.

Основой ведения беременности при СД является контроль уровня гликемии при помощи биохимических тестов и терапевтическая коррекция. Достижение хорошего гликемического контроля к моменту наступления беременности и его поддержка на протяжении беременности снижает акушерские и перинатальные риски, но не устраняет их полностью [3].

На современном этапе у большинства женщин с СД течение беременности и состояние внутриутробного плода бывает благоприятным, что связано с эффективной медикаментозной коррекцией патологии. Беременная с хорошим контролем гликемии и отсутствием сосудистой патологии, по мнению большинства перинатологов, имеет средне-популяционный риск неблагоприятного перинатального результата [6].

В то же время, хотя неконтролируемый диабет практически не встречается в акушерской и перинатальной практике на современном этапе, при декомпенсации или при субоптимально контролируемой гликемии имеются возможности для развития фетопатии. Частота фетопатии и перинатальных осложнений строго коррелирует с уровнем гликемии беременной [5].

Как уже было отмечено, даже при строгом метаболическом контроле матери, т.е. даже при контролируемом нормогликемическом СД, у плода может формироваться диабетическая фетопатия, и в подобных случаях способа диагностики, равнозначного ультразвуковому (УЗ) мониторингу, не существует [7]. Эхография является неинвазивным и легко доступным способом оценки и мониторинга плода при беременности, осложненной СД [5].

Среди эхографических предикторов и диагностических критериев фетального неблагополучия, связанного с материнским СД, известны следующие: макросомия (ее асимметричный тип с преимущественным увеличением окружности живота), многоводие, диабетическая гипертрофическая миокардиопатия, гепатомегалия и подкожный отек плода $[8,9,10]$.

В большинстве случаев у плодов диабетических матерей развивается макросомия, гораздо реже - наблюдается задержка роста плода (ЗРП), связанная с диабетической нефропатией либо с сочетанной преэклампсией у матери [5]. ЗРП при диабете манифестирует в начале III триместра, чаще имеет асимметричные черты. В диагностике ЗРП эхографическая фетометрия оптимальна в сравнении с измерением высоты дна матки [5]. Что касается макросомии плода, некоторые авторы считают, что ее клиническая диагностика не уступает в эффективности эхографической фетометрии, при этом оба способа недостаточно эффективны и имеют низкую чувствительность за счет переоценки либо недооценки предполагаемого веса плода $[11,12]$. Например, по недавно опубликованным данным чешского перинатального центра, из 292 беременных женщин с СД диабетическая фетопатия встречалась у 39 (10\%), при этом эффективность УЗ диагностики фетопатии была весьма низкой, на уровне 38\% [13]. Авторы ряда исследований считают, что эхографическая диагностика фетопатии при СД беременных ненадежна и требует усовершенствования [5].

Предпринимаются попытки оценки т.н. инсулино-чувствительного слоя подкожной жировой клетчатки плода, как критерия фетальной гиперинсулинемии [5]. Было показано, что оценка толщины жировой клетчатки туловища плода сильнее коррелирует с материнским гликемическим контролем и эффективнее предсказывает фетальную гиперинсулинемию и диабетическую макросомию, чем расчет веса плода $[14,5]$.

При выработке акушерской и перинатальной тактики одним из наиболее сложных моментов является оценка риска развития РДС и прогнозирование дыхательной функции после рождения. С одной стороны - пролонгирование беременности при фетопатии способствует прогрессивному ухудшению состояния внутриутробного плода. С другой стороны, фетопатия повышает риск РДС новорожденного, таким образом, досрочное родоразрешение при материнском СД само по себе может явиться негативным ятрогенным воздействием. На разных этапах изучения акушерского диагностического ультразвука предпринимались попытки анализа эхографической картины легких плода для прогноза их функции после рождения, в частности, изучение звукопроводимости легких в сравнении со звукопроводимостью печени плода. Ранее существовали мнения о взаимосвязи между эхографическими характеристиками легких плода и их зрелостью, а также между зрелостью плаценты и зрелостью легких. Эти представления в настоящее время многие эксперты пренатальной эхографии считают ошибочными, т.к. при работе на современных сканерах высокая эхогенность 
легких определяется намного раньше, чем возможно их созревание с точки зрения нормальной физиологии [15]. Тем не менее, некоторые исследователи изучают возможность диагностики зрелости легких плода на основании их УЗ изображения и предлагают уделять внимание этому аспекту антенатальной эхографии при СД беременных [16].

Таким образом, эхографический мониторинг является одним из ведущих способов антенатального наблюдения при СД [5]. Согласно современным рекомендациям и клиническим протоколам, мониторинг роста и состояния плода и амниометрию у женщин с СД проводят 1 раз в 4 недели после 28 недель беременности [17,18]. При наличии ЗРП рекомендуются допплеровские исследования дважды в неделю с целью диагностики декомпенсации плода [19]. В то же время, в действующих рекомендациях подчеркивается, что допплеровские исследования при диабетической макросомии плода не являются информативными [19].

Хотя эхография является эффективным акушерским инструментом и широко используется для оценки состояния плода, на сегодняшний день отсутствует четкий регламент ведения беременности при СД в зависимости от УЗ изменений [5]. Это связано с отсутствием убедительных доказательств, которые основывались бы на результатах крупных рандомизированных контролируемых ис-

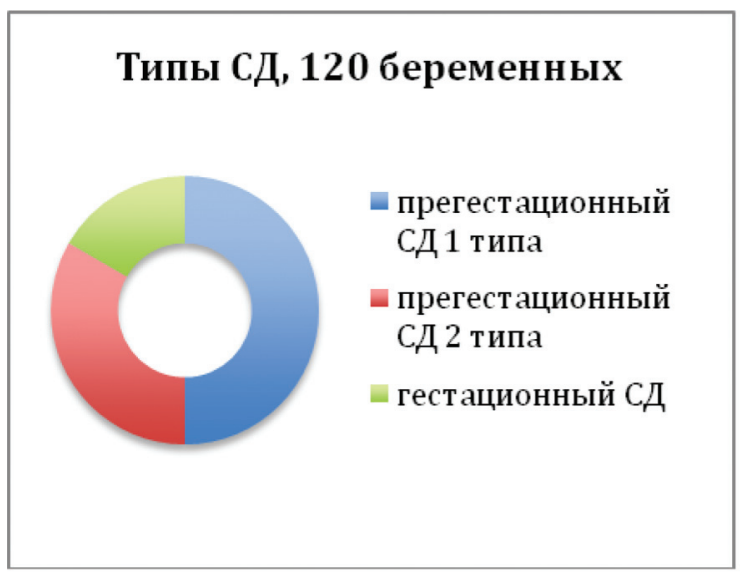

Рис. 1. Типы СД, 120 беременных женщин

УЗ исследования до рождения включали визуальную оценку анатомии плода, стандартную фетометрию, измерение длины печени, размеров сердца плода с вычислением кардио-торакального отношения (КТО), измерение толщины подкожного буккального жира и жирового слоя туловища (передней брюшной стенки и над лопаткой плода), сравнение звукопроводимости легких и печени плода, а также оценку степени зрелости плаценты и индекса амниотической жидкости (amniotic fluid index, AFI). Проводилась допплерометрия артерии пуповины (АП), маточных артерий (МА), фетальной средней мозговой артерии (СМА). Церебро-плацентарное отношение (ЦПО) рассчитывалось как отношение пульсационных следований, поскольку организация таких исследований практически невозможна. Разработка критериев диагностики фетопатии и прогнозирования перинатального результата, особенно в случаях субоптимально контролируемой гликемии - это важный аспект антенатального наблюдения и пренатального консультирования при СД беременной и важная задача современной перинатологии.

Цель работы - изучение возможностей антенатальных эхографических мониторингов в диагностике диабетической фетопатии и определении степени перинатального риска при сахарном диабете беременных.

\section{Материал и методы}

Дизайн - проспективное когортное обсервационное одноцентровое исследование. На антенатальном этапе были эхографически обследованы 120 беременных женщин с СД. Из них прегестационный СД 1 типа имели 60 беременных, прегестационный СД 2 типа - 40, гестационный СД - 20 женщин (рис.1).

$3 / 120$ (2,5\%) женщин имели неконтролируемую гликемию. Субоптимально контролируемая гликемия наблюдалась у $31 / 120$ (25,8\%) беременных с СД. Хороший гликемический контроль имел место у 89/120 (74,1\%) беременных с СД (рис.2).

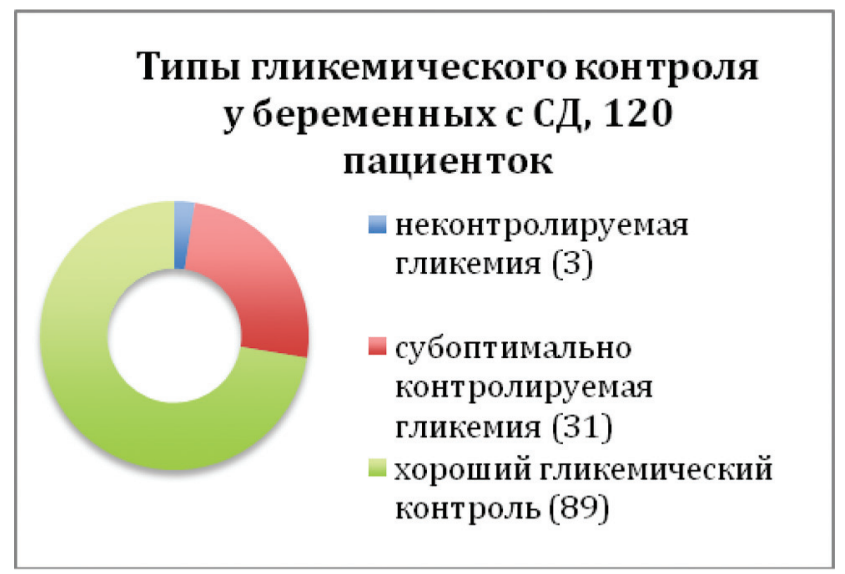

Рис. 2. Типы гликемического контроля, 120 беременных женщин с СД

индексов СМА и АП. Изученные постнатальные результаты обследованных женщин классифицировались следующим образом: неблагоприятный общий постнатальный результат (ОПР) - перинатальная или младенческая смерть, метаболический ацидоз при рождении, оценка 0-4 баллов по шкале Апгар при рождении; неблагоприятный клинический постнатальный результат (КПР) тяжелая неонатальная заболеваемость, тяжелая персистирующая постнатальная заболеваемость.

УЗ исследования и архивирование УЗ имиджей выполнялись на аппаратах Voluson 730 pro (GE, США) и Philips HD 11 (Германия). Исследования выполнялись в отделении УЗ диагностики КУЗО Областная больница «Центр экстренной медицин- 
ской помощи и медицины катастроф», в структуре которого до 2012 г функционировали отделения патологии беременных и родильное отделение, а с 2012 г - региональный перинатальный центр. Операционные характеристики эхографических критериев расчитывались методом логистической регрессии при помощи четырехпольных таблиц с определением коэффициентов отношения шансов (OR) и отношения рисков (RR) при доверительном интервале (confidence interval, CI) 95\%.

\section{Результаты и их обсуждение}

У 3/120 (2,5\%) плодов встречались структурные аномалии (эмбриопатии): синдром каудальной регрессии (сакральной агенезии) (рис.3), тетрада Фалло, а также первичный гидроуретер (мегауретер) (рис.4). Неблагоприятные ОПР имели место в катамнезе 8/120 (6,6\%) плодов, неблагоприятные КПР (РДС, неонатальная реанимация, ПИТ, оценка 4-7 баллов по шкале Апгар при рождении, неонатальная гипогликемия, другие неонатальные осложнения) - в катамнезе 11/120 $(9,1 \%)$ плодов, мониторированных до рождения.
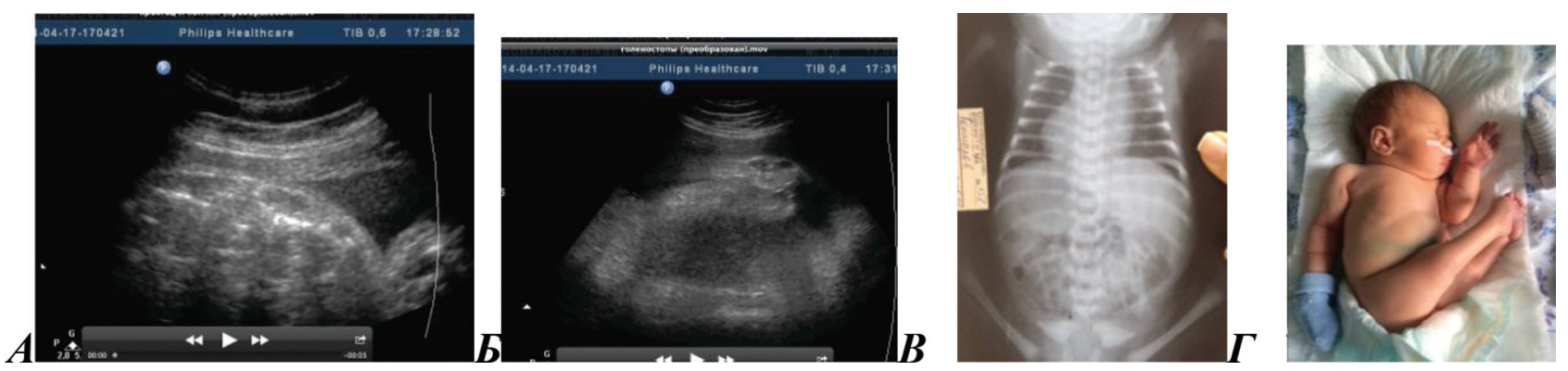

Рис. 3. Беременность на фроне тяжелого СД I типа. Эмбриопатия плода: синдром каудальной регрессии (сакральной агенезии): А). поперечное сечение нижнего отдела туловища плода на уровне дистального отдела позвоночника и тазовых костей, агенезия крестца и поясничных позвонков, сочленение каудального позвонка и тазовых костей (антенатальная эхограмма); Б). контрактура голеностопных суставов, гипоплазия голеней и дисплазия стоп плода (антенатальная эхограмма); В). дисплазия каудального отдела позвоночника и костей таза, дефект между подвздошными костями (рентгенограмма новорожденного); Г). фрото новорожденного
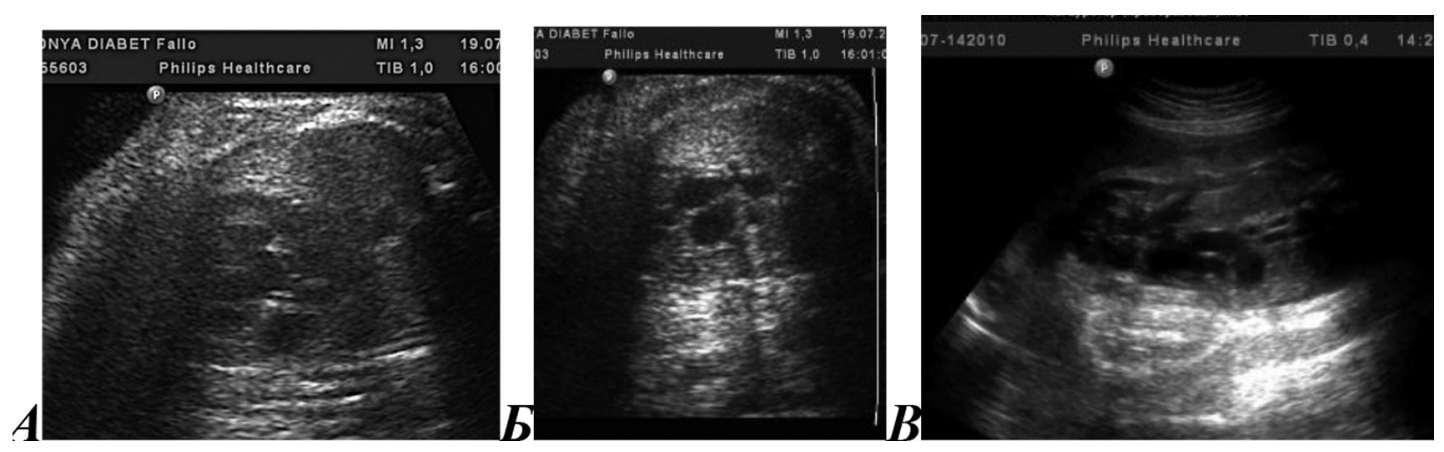

Рис. 4. Эмбриопатии при беременности на фоне тяжелого СД I типа, 2 случая: А,Б). тетрада Фалло у плода; В). первичный гидроуретер (мегауретер) плода

3 случая неконтролируемой гликемии были связаны с поздним взятием на учет по беременности, неадекватным социальным поведением женщин, несвоевременной диагностикой гестационного либо предгестационного диабета. Во всех этих случаях ОПР были неблагоприятными (антенатальная или ранняя неонатальная смерть). Общее число плодов и новорожденных с неблагоприятными ОПР и КПР составило в изученной когорте 19/120 $(15,8 \%) .15 / 120(12,5 \%)$ женщин имели в исходе беременности преждевременные роды, у 15/120 $(12,5 \%)$ СД сочетался с гипертензивными нарушениями и преэклампсией.

У $17 / 120$ (14\%) новорожденных наблюдались клинические проявления синдрома диабетической фетопатии после рождения в виде различных комбинаций симптомов: макросомии, гипогликемии, диабетической гипертрофической миокардиопатии (МКП), неиммунного отека подкожной клетчатки, гепато-спленомегалии, РДС. На антенатальном этапе у плодов с фетопатией выявлялись различные эхографические изменения (табл. 1). Таблица также содержит данные об операционных характеристиках в диагностике диабетической фетопатии различных антенатальных особенностей: типа гликемического контроля беременной, а также эхографических и допплеровских изменений. 
Таблиця 1

\begin{abstract}
Операционные характеристики различных антенатальных особенностей (типа гликемического контроля, эхографических и допплеровских критериев) в диагностике диабетической фетопатии

(120 плодов от матерей с СД, 17 плодов и новорожденных с фетопатией)
\end{abstract}

\begin{tabular}{|c|c|c|c|c|c|c|c|c|}
\hline № & $\begin{array}{c}\text { Эхографические и допплеровские } \\
\text { изменения }\end{array}$ & $\mathrm{n} 1$ & $\mathrm{n} 2$ & $\mathrm{Se}, \%$ & $\mathrm{Sp}, \%$ & Ac, $\%$ & OR & RR (при CI 95\%) \\
\hline 1 & $\begin{array}{c}\text { Двойной контур головки плода } \\
\text { (подкожный отек) } 5+\text { мм } \\
\end{array}$ & 47 & 10 & 70 & 60 & 61 & 4,08 & $3,34(3,79-5,91)$ \\
\hline 2 & $\begin{array}{c}\text { Высокорезистентный кровоток (ВРК) } \\
\text { МА }\end{array}$ & 21 & 2 & 22 & 78 & 74 & 1,0 & $1,1(0,07-1,18)$ \\
\hline 3 & Низкорезистентный кровоток СМА & 9 & 1 & 8 & 86 & 81 & 1,2 & $1,15(0,08-1,22)$ \\
\hline 4 & $\begin{array}{c}\text { Гепатомегалия (продольный размер } \\
\text { печени выше 90-го процентиля) }\end{array}$ & 6 & 2 & 12 & 92 & 81 & 3,28 & $2,21(1,1-2,7)$ \\
\hline 5 & Хорошо контролируемая гликемия & 89 & 7 & 21 & 62 & 4 & 0,003 & $0,47(0,21-1,08)$ \\
\hline 6 & $\begin{array}{c}\text { Толщина п/к буккального жира плода } \\
5+\text { мм }\end{array}$ & 35 & 6 & 35 & 71 & 66 & 1,42 & $1,33(0,04-1,96)$ \\
\hline 7 & $\begin{array}{l}\text { Субоптимально контролируемая } \\
\text { гликемия }\end{array}$ & 31 & 11 & 64 & 79 & 77 & 8,0 & $6,0(4,82-8,36)$ \\
\hline 8 & $\begin{array}{c}\text { Толщина п/к жира туловища плода } \\
5+\text { мм } \\
\end{array}$ & 9 & 3 & 17 & 93 & 83 & 3,35 & $2,65(1,90-3,6)$ \\
\hline 9 & $\begin{array}{c}\text { Гипертрофическая МКП с увеличени- } \\
\text { ем КТО } \\
\end{array}$ & 7 & 5 & 33 & 91 & 83 & 3,45 & $4,0(3,17-5,43)$ \\
\hline 10 & $\begin{array}{c}\text { Двойной контур головки плода } \\
\text { (подкожный отек) до } 5 \text { мм }\end{array}$ & 40 & 10 & 56 & 85 & 78 & 3,0 & $2,6(1,88-3,31)$ \\
\hline 11 & $\begin{array}{c}\text { Постоянный нулевой диастолический } \\
\text { кровоток (ПНДК) АП }\end{array}$ & 9 & 2 & 9 & 92 & 80 & 1,25 & $1,28(1,02-2,74)$ \\
\hline 12 & Многоводие & 7 & 3 & 11 & 94 & 82 & 2,33 & $2,1(1,08-3,34)$ \\
\hline 13 & $\begin{array}{c}\text { Макросомия симметричная } \\
\text { (рассчитанный вес плода выше 90-го } \\
\text { процентиля) }\end{array}$ & 16 & 5 & 29 & 89 & 80 & 3,46 & $2,81(1,14-3,42)$ \\
\hline 14 & ВРК АП & 20 & 4 & 26 & 85 & 76 & 1,1 & $0,91(0,07-1,14)$ \\
\hline 15 & $\begin{array}{c}\text { Макросомия асимметричная (AC } \\
\text { выше 90-го процентиля) }\end{array}$ & 11 & 4 & 25 & 93 & 83 & 5 & $3,5(2,06-3,92)$ \\
\hline
\end{tabular}

n1 - частота признака в общем числе наблюдений,

n2 - частота признака среди плодов с фетепатией,

$\mathrm{Se}$ - чувствительность,

Sp - специфичность,

Ac - точность

Диаграммы иллюстрируют диагностическое и прогностическое значение различных показателей антенатальных эхографических и допплеровских мониторингов в диагностике диабетической фетопатии (рис.5), а также неблагоприятных ОПР (рис.6) при материнском СД.

Такие антенатальные факторы, как субоптимально контролируемая гликемия (RR 6,0, 4,88,32 при CI 95\%), двойной контур головки плода 5+мм (RR 3,34, 3,79-5,91 при CI 95\%), гипертрофическая МКП с увеличением КТО (RR 4,0, 3,175,43 при CI 95\%), толщина п/к жира передней брюшной стенки 5+мм (RR 2,65, 1,90-3,6 при CI 95\%) - имели наибольшее значение для предсказания диабетической фетопатии при рождении.

Связи средней силы с клиническими проявлениями диабетической фетопатии демонстрировали следующие антенатальные критерии: макросомия асимметричная при АС выше 90-го процентиля, многоводие, макросомия симметричная (рассчитанный вес выше 90-го процентиля), двойной контур голо- вки плода (подкожный отек) до 5 мм, постоянный нулевой диастолический кровоток (ПНДК) АП, также гепатомегалия.

Наименьшее прогностические значение для антенатальной детекции диабетической фетопатии при рождении (RR 0,04-1,96 при CI 95\%) имели такие признаки, как хорошо контролируемая гликемия, допплеровские изменения (высокорезистентный кровоток, ВРК) МА, АП, допплеровские изменения СМА, а также толщина подкожного слоя буккального жира лица плода (жирового слоя, не являющегося инсулино-зависимым у плода). Таким образом, рассчитанный вес плода, превышающий значения 90-го процентиля для гестационного срока, также как и толщину буккального жира плода, нельзя считать надежными предикторами диабетической фетопатии, поскольку невозможно точно сказать, имеет ли место конституциональная тенденция роста либо макросомия, связанная с избыточным питанием (т.е. с гипергликемией) плода. Толщина инсулин-чувствительного подкожного жирового слоя 
передней брюшной стенки плода в нашем исследовании явилась более надежным предиктором фетопатии, чем предполагаемая симметричная либо асимметричная макросомия.

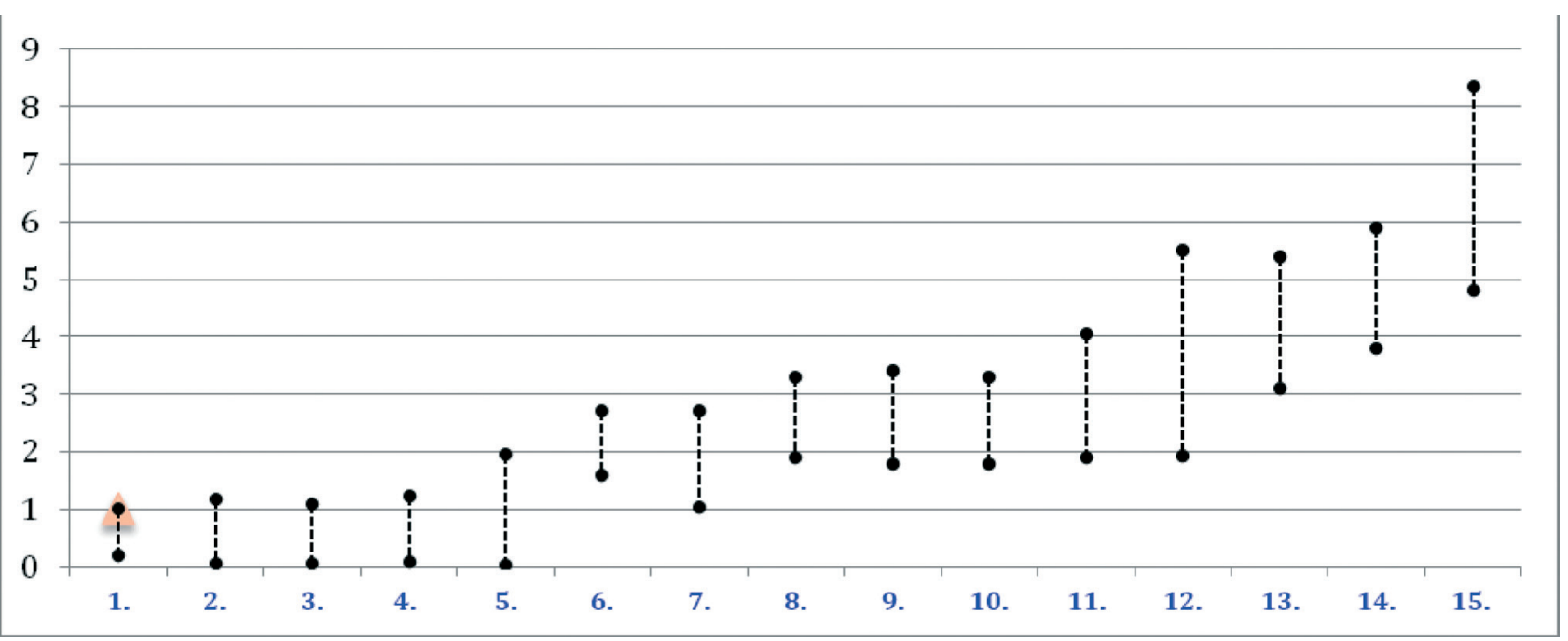

Рис. 5. Результаты антенатальных мониторингов 120 плодов от матерей с СД, 17 плодов и новорожденных с фетопатией. Отношения рисков развития диабетической фетопатии (RR при Cl 95\%) при различных типах гликемического контроля, а также различных антенатальных эхографических и допплеровских изменениях: 1-хорошо контролируемая гликемия; 2-ВРК МА; 3-ВРК АП; 4-допплер СМА; 5-толщина п/к буккального жира; 6-гепатомегалия (продольный размер печени выше 90-го процентиля);

7-ПНДК АП; 8-двойной контур головки плода (подкожный отек) до 5 мм; 9-макросомия симметричная (рассчитанный вес выше 90-го процентиля); 10-многоводие; 11-макросомия асимметричная (AC выше 90го процентиля); 12-толщина п/к жира передней брюшной стенки 5+мм; 13-гипертрофическая МКП; 14-двойной контур головки плода (подкожный отек) 5+ мм; 15-субоптимально контролируемая гликемия

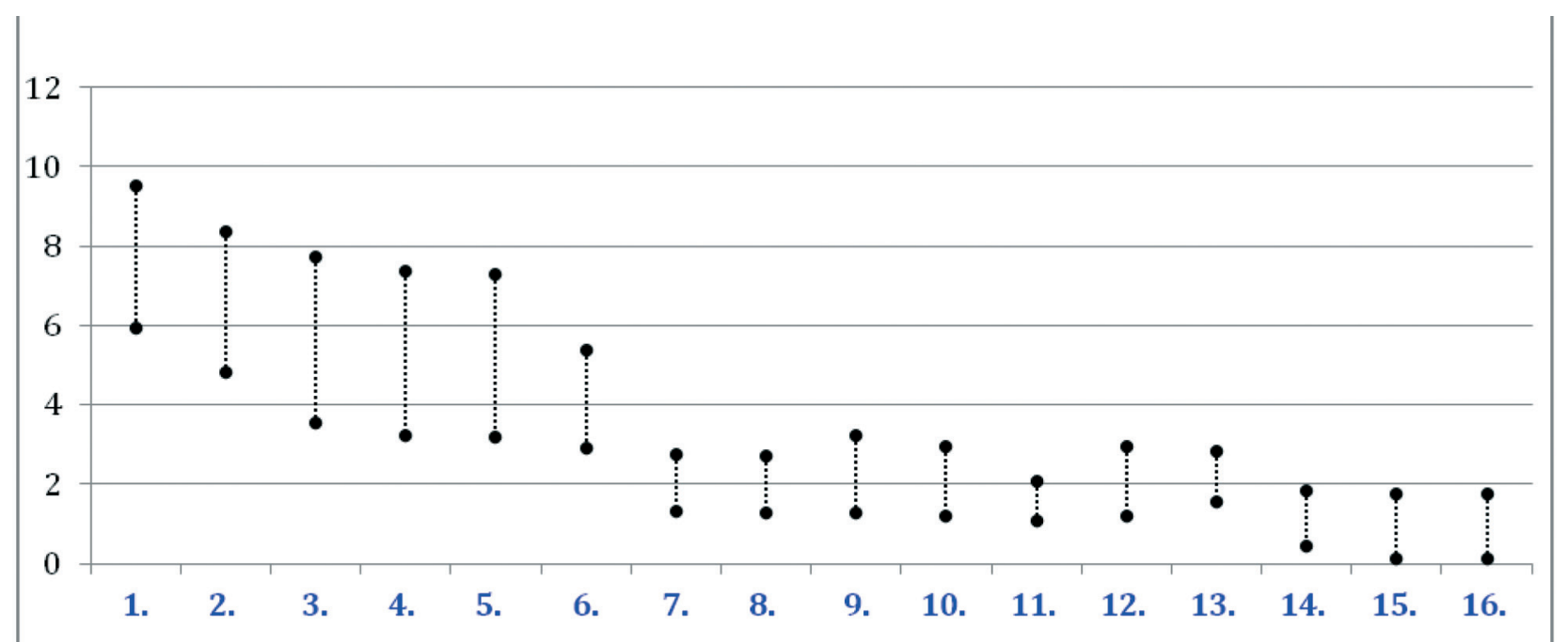

Рис. 6. Результаты антенатальных мониторингов 120 плодов от матерей с СД, 8 плодов и новорожденных с неблагоприятным ОПР. Отношения рисков (RR при CI 95\%) неблагоприятных ОПР у плодов от матерей с СД при различных антенатальных эхографических и допплеровских изменениях: 1-неконтролируемая гликемия; 2-субоптимально контролируемая гликемия; 3-3РП при СД; 4-ПНДК АП; 5-допплер СМА; 6-ЦПО<1; 7-двойной контур головки плода (подкожный отек) 5+мм; 8-макросомия асимметричная (АС выше 90-го процентиля); 9-макросомия симметричная (рассчитанный вес выше 90-го процентиля); 10-толщина п/к жира туловища более 5 мм; 11-ИНДК АП; 12-многоводие; 13-гипертрофическая МКП; 14-ВРК АП; 15-ВРК МА; 16-хорошо контролируемая гликемия

Сильные связи с неблагоприятными ОПР при рождении (RR 9,53-2,9 при 95\% CI) демонстрировали такие антенатальные предикторы, как неконтролируемая и субоптимально контролируемая гликемия, ЗРП при СД, ПНДК АП, допплеровские изменения СМА и ЦПО $<1$. Таким образом, эхографические признаки плацентарной дисфункции (такие как ЗРП и допплеровские изменения АП и/или СМА) в нашем исследовании явля- лись важными и универсальными предикторами высокого перинатального риска и неблагоприятного результата беременности, хотя при этом не являлись предикторами собственно диабетической фетопатии. Неблагоприятные результаты беременности были связаны в таких случаях с сосудистыми поражениями почек матери и имели более серьезное значение, чем предикторы типичной диабетической фетопатии. 
Связи средней силы (RR 1,55-2,75 при CI 95\%) c неблагоприятными результатами беременности имели такие пренатальные эхографические предикторы, как асимметричная макросомия, симметричная макросомия, толщина п/к жира передней брюшной стенки 5+ мм, интермиттирующий нулевой диастолический кровоток (ИНДК) АП, многоводие, гепатомегалия и гипертрофическая МКП.

Не имели значения (RR 0,04-1,96 при CI 95\%) для предсказания неблагоприятного ОПР при материнском СД такие антенатальные критерии, как гемодинамические изменения по типу ВРК АП и
MA, а также хорошо контролируемая гликемия.

Диаграмма на рис.7 иллюстрирует невозможность прогнозирования РДС после рождения при материнском СД на основании результатов эхографической оценки фетальных легких (эхограммы на рис.9), также как и на основании наличия или отсутствия признаков зрелости плаценты. Рассчитанные значения RR развития РДС после рождения определялись в диапазоне от 0,5 до 1,46 , т.е. антенатальные эхографические мониторинги нельзя считать эффективными в прогнозировании функциональной зрелости легких и развития РДС у новорожденных от матерей с СД.

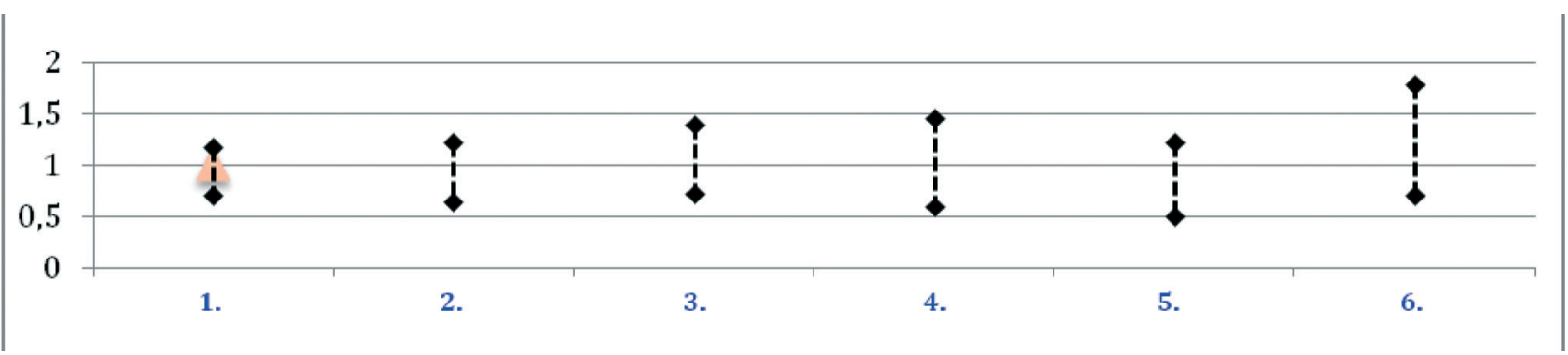

Рис. 7. Результаты антенатальных мониторингов 120 плодов от матерей с СД, 11 новорожденных с РДС. Отношения рисков развития РДС при рождении (RR при CI 95\%) при различных антенатальных эхографических особенностях: 1-звукопроводимость легких ниже звукопроводимости печени; 2-звукопроводимость легких соответствует звукопроводимости печени; 3-звукопроводимость легких выше звукопроводимости печени; 4-І степень зрелости плаценты; 5-ІІ степень зрелости плаценты; 6-ІІІ степень зрелости плаценты
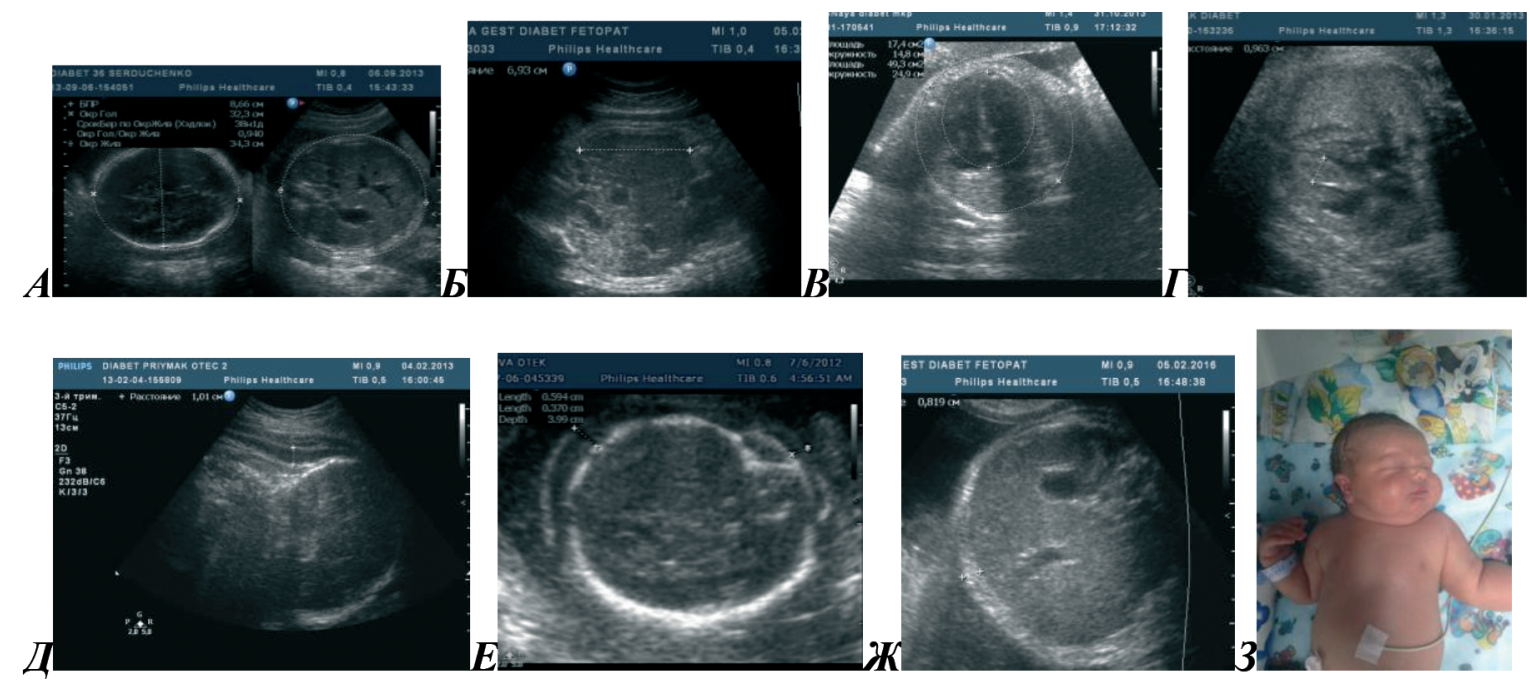

Рис. 8. Антенатальные эхографические признаки диабетической фетопатии: А). асимметричная макросомия (значение АC выше 90-го процентиля); Б). длина печени плода 5,2 см (выше 90-го процентиля); В). увеличение КТО за счет МКП; Г). гипертрофия миокарда желудочков и МЖП; Д). подкожный отек плода 10 мм, задняя шейная область; Е). подкожный отек плода 6 мм, двойной контур головки; ж). фото новорожденного

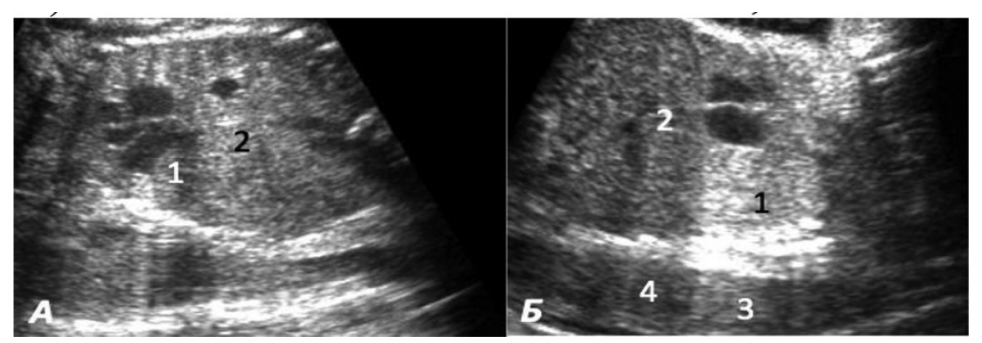

Рис. 9. Сравнительная эхогенность и звукопроводимость легких и печени плода, не имевшая взаимосвязи с РДС при рождении: А). звукопроводимость легких и печени одинаковая; Б). эхогенность и звукопроводимость ткани легких (1) выше звукопроводимости печени (2): за дистальным краем легкого определяется сигнал более высокой эхогенности (3), чем за дистальным краем печени (4) 


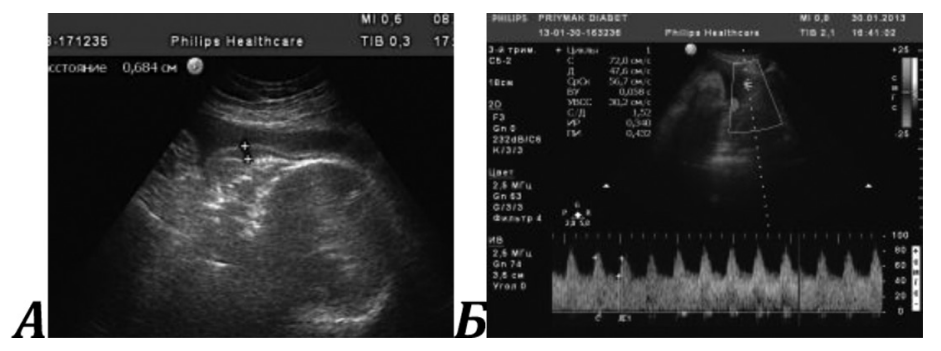

Рис. 10. Эхографические признаки, не имевшие выраженной связи с диабетической фетопатией, РДС при рождении и перинатальным результатом: толщина буккального подкожного жира более 0,5 мм (А) и нормальный допплер АП (Б) в 37-38 недель у плода с диабетической фетопатией при рождении и тяжелыми неонатальными осложнениями

\section{Выводы}

Общее число плодов и новорожденных с неблагоприятными ОПР и КПР при СД беременных составило 19/120 (15,8\%). Неблагоприятные ОПР наблюдались в катамнезе 8/120 (6,6\%) плодов.

Результаты антенатальных УЗ мониторингов при СД строго зависят от типа гликемического контроля. Субоптимально контролируемая гликемия, двойной контур головки плода (подкожный отек) более 5 мм, гипертрофическая МКП с увеличением КТО более 0,3 , толщина п/к жира передней брюшной стенки 5+ мм имели наибольшее значение для предсказания диабетической фетопатии при рождении. Толщина инсулин -чувствительного подкожного жирового слоя туловища плода в исследованной когорте явилась более надежным предиктором фетопатии, чем предполагаемая сим- метричная либо асимметричная макросомия.

Эхографические признаки плацентарной дисфункции (ЗРП и допплеровские изменения АП и/или СМА) в исследованной когорте были важными и универсальными предикторами высокого перинатального риска и неблагоприятного результата беременности, хотя при этом не являлись предикторами собственно диабетической фетопатии. Не имели диагностического и прогностического значения для ОПР при материнском СД такие антенатальные критерии, как гемодинамические изменения по типу ВРК АП и MA, а также хорошо контролируемая гликемия. Антенатальные эхографические мониторинги нельзя считать эффективными в прогнозировании функциональной зрелости легких и развития РДС у новорожденных от матерей с СД.

\section{Література}

1. Ефективний антенатальний догляд: навч. посіб.- К.2012.- 509 с.

2. Managing type 1 diabetes mellitus in pregnancy-from planning to breastfeeding/ L. Ringholm, E.R. Mathiesen, L. Kelstrup [et al.] // Nature Reviews Endocrinology.- 2012.- Vol.8.-P.659-67.

3. Executive Summary: Standards of Medical Care in Diabetes // Diabetes Care.- 2010.- Vol.33(1)--P.3-61.

4. Ордынский В.Ф. Сахарный диабет и беременность: Пренатальная ультразвуковая диагностика / В.Ф. Ордынский, О.В. Макаров.- М.: Видар, 2010.-С.49-76.

5. Dupak J.D.L. Ultrasound Surveillance in Pregnancy Complicated by Diabetes / J.D.L. Dupak, A.L. Trujillo // Diabetes Spectrum.- 2007.- Vol.20.-P.289-93.

6. Perinatal mortality in diabetic patients undergoing antepartum fetal evaluation: a case-control study / A.

Brecher, T. Tharakan, A. Williams [et al.] // J Matern Fetal Neonatal Med.- 2002.- Vol.12.-P.423-427.

7. Severe diabetic fetopathy despite strict metabolic control / H. Leipold, S. Worda, L. Schwindt [et al.] // Wein klin Wochenschr.-2005.- Vol.117(15-16).-P.561-4.

8. Hornberger L.K. Maternal diabetes and the fetal heart / L.K. Hornberger // Heart.- 2006.Vol.92.-P.1019-1021.

9. Litvinova M. F. Pathogenesis of fetal hypertrophic cardiomyopathy in insulin-dependent diabetes mellitus

/ M.F. Litvinova // Bulletin for experimental Biology and Medicine.- 1996.- Vol.121.-P.698-701.

10. Assessment of fetal liver volume and umbilical venous volume flow in pregnancies complicated by insulindependent diabetes mellitus / SM. Boito, PC. Struijk, NT. Ursem [et al.] // BJOG.-2003.- Vol.110(11).-P.1007-13.

11. Clinical and sonographical estimation of fetal weight performed during labor by residents / G. Noumi, F. Collado-Khoury, A. Bombard [et al.] // Am J Obstet Gynecol.- 2005.- Vol.192.-P.1407-9.

12. Reliability of ultrasound estimation of fetal weight in term singleton pregnancies / A. Colman, D. Maharaj, J. Hutton [et al.] // NZ Med J.- 2006.- Vol.119.-P.2146.

13. Results of perinatal care of pregnant women with diabetes in Western Bohemia / V. Korecko, J. Landsmanova, A. Moskova [et al.] // Ceska Gynekol.- 2014.- Vol.79(1).-P.43-7.

14. Increased fetal adiposity: a very sensitive marker of abnormal in utero development / P. Catalano, A. Thomas, L. Huston-Presley [et al.] // Am J Obstet Gynecol.- 2003.- Vol.189.-P.1698-1704.

15. Callen P.W. Ultrasonography in Obstetrics and Gynecology / P.W. Callen.- Elsevier Health Sciences, 2011. -1180 p.

16. Fetal lung maturity analysis using ultrasoundImage features. B.K.N. Bhanu Prakash, A.G. Ramakrishnan, S. Suresh [et al.] // IEEE transactions on information technology in biomedicine.- 2002.- Vol.6(1).-P.38-45. 
17. Клінічний протокол «Ведення вагітності у хворих на передгестаційний діабет» // Наказ МОЗ України від 15.12.2003.

18. Visser G. Antenatal follow-up and decision concerning timing and mode of delivery / G. Visser // The 7th international DIP symposium Diabetes, Hypertension, Metabolic Syndrome\&Pregnancy, Florence, Italy, March 13-16, 2013.

19. Maulik D. Umbilical arterial Doppler sonography for fetal surveillance in pregnancies complicated by pregestational diabetes mellitus / D. Maulik, A. Lysikiewicz, G. Sicuranza // J Mat Fet Neonatal Med.- 2002.- Vol.12.-P.417-422.

\section{МОЖЛИВОСТІ АНТЕНАТАЛЬНИХ ЕХОГРАФІЧНИХ МОНІТОРИНГІВ ПРИ ЦУКРОВОМУ ДІАБЕТІ ВАГІТНИХ В ДІАГНОСТИЦІ ДІАБЕТИЧНОЇ ФЕТОПАТІЇ І ВИЗНАЧЕННІ СТУПЕНЯ ПЕРИНАТАЛЬНОГО РИЗИКУ}

\section{I.М. Сафонова}

Харківська медична академія післядипломної освіти МЗ України

(м.Харків, Україна)

\section{Резюме.}

Мета роботи - вивчення можливостей антенатальних ультразвукових (УЗ) моніторингів в діагностиці діабетичної фетопатії і визначенні ступеня перинатального ризику при цукровому діабеті (ЦД) вагітних.

Матеріал і методи. Проспективное когортне обсерваційне одноцентрове дослідження. Ехографічно обстежені 120 вагітних жінок з ЦД: 3 $(2,5 \%)$ - з неконтрольованою глікемією, 31 (25,8\%) - 3 субоптимально контрольованою глікемією, 89 $(74,1 \%)$ - 3 хорошим глікемічним контролем. Дослідження до народження включали візуальну оцінку анатомії плода, стандартну фетометрію, вимірювання довжини печінки, розмірів серця плоду, товщини підшкірного буккального жиру і жирового шару тулуба плоду (передньої черевної стінки і над лопаткою), порівняння звукопровідності легенів і печінки плода, оцінку індексу амніотичної рідини. Проводилась доплерографія артерії пуповини (АП), маткових артерій (МА), фетальної середньої мозкової артерії (CMA). Постнатальні результати класифікувалися як несприятливий загальний постнатальний результат, ЗПР (перинатальна або малюкова смерть, метаболічний ацидоз при народженні, оцінка 0-4 балів за шкалою Апгар) і несприятливий клінічний постнатальний результат, КПР (персистуюча постнатальная захворюваність).

Результати. У 3/120 (2,5\%) плодів зустрічалися структурні аномалії (ембріопатіi). Синдром діабетичної фетопатії був у 17/120 (14\%) новонароджених. Загальна кількість плодів і новонароджених 3 несприятливими ЗПР і КПР склала 19/120 (15,8\%): несприятливі ЗПР мали 8/120 (6,6\%), несприятливі КПР-11/120 (9,1\%) плодів. Антенатальні фактори, що мали найбільше значення для передбачення діабетичної фетопатії при народженні: субоптимально контрольована глікемія (RR 6,0, 4,8-8,32 при CI 95\%), подвійний контур голівки плоду (п/ш набряк) 5+мм (RR 3, 34, 3,79-5,91 при CI 95\%), гіпертрофічна міокардіопатія (RR 4,0, 3, 17-5,43 при

\section{FEATURES OF ANTENATAL ULTRASONOGRAPHIC MONITORING IN DIABETES MELLITUS PREGNANT WOMEN IN THE DIAGNOSIS OF DIABETIC FETOPATHY AND DETERMINING THE DEGREE OF PERINATAL RISK}

\section{Safonova}

\author{
Kharkiv Medical Academy of Postgraduate \\ Education \\ (Kharkov, Ukraine)
}

\section{Summary.}

Purpose - to explore the possibilities of antenatal ultrasound (US) monitoring in the diagnosis of diabetic fetopathy and determining the degree of perinatal risk in diabetes mellitus (DM) pregnant women.

Material and methods. Prospective cohort observational single-center study. 120 pregnant women with DM were held US monitoring: $3(2.5 \%)$ of them had uncontrolled glycemia, $31(25.8 \%)$ had suboptimally controlled glycemia and 89 (74.1\%) women had good glycemic control. Research before birth include the visual assessment of fetal anatomy, standard fetometry, measurement of fetal liver length, fetal heart size, the thickness of subcutaneous buccal fat and fat layer of fetal trunk (at anterior abdominal wall and over the shoulder blade), the comparison of fetal lungs and liver echogenicity as well as amniotic fluid index estimation. The fetuses underwent Doppler velocimetry of umbilical artery (UA), uterine arteries (UtA) and middle cerebral artery (MCA). Postnatal results were classified as follows: adverse general postnatal outcome (GPO) meant perinatal or infant death; adverse clinical postnatal outcome (CPO) meant severe neonatal morbidity.

Results. $3 / 120(2,5 \%)$ fetuses had structural abnormalities (embryopathy). 17/120 (14\%) newborns had diabetic fetopathy syndrome. The total number of fetuses and infants with adverse GPO and CPO were $19 / 120(15,8 \%)$, there were $8 / 120(6,6 \%)$ those with unfavorable GPO and 11/120 (9.1\%) with unfavorable CPO. Antenatal features that were the most important for prediction of diabetic fetopathy at birth were the next: suboptimally controlled glycemia (RR 6,0, 95\% CI $4,8-8,32$ ), a double loop of the fetal head $5+\mathrm{mm}$ (subcutaneous edema) (RR 3,34, 95\% CI 3,79-5,91), hypertrophic cardiomyopathy (RR 4,0, 95\% CI 3,17$5,43)$, the thickness of subcutaneous fetal body fat $5+\mathrm{mm}$ (RR 2,65, 95\% CI 1,90-3,6). The thickness of the insulin-sensitive subcutaneous fetal body fat layer is more reliable predictor of fetopathy than assumed to be symmetric or asymmetric macrosomia. Such 
CI 95\%), товщина підшкірного жиру тулуба плода 5+мм (RR 2, 65, 1,90-3,6 при CI 95\%). Товщина інсулін-чутливого підшкірного жирового шару тулуба плода була більш надійним предиктором фетопатии, ніж передбачувана симетрична або асиметрична макросомія. Сильні зв'язки з несприятливими ЗПР (RR 9,53-2,9 при 95\% CI) демонстрували такі антенатальні предиктори, як неконтрольована і субоптимально контрольована глікемія, затримка росту плода (ЗРП), допплерівські зміни АП та СМА. Тобто ехографічні ознаки плацентарної дисфункції при СД (ЗРП і допплерівські зміни АП та / або СМА) були важливими і універсальними предикторами високого перинатального ризику і несприятливого результату вагітності, хоча при цьому не були предикторами власне діабетичної фетопатії. Високорезистентний кровотік АП і МА, a також добре контрольована глікемія, не мали діагностичного та прогностичного значення (RR 0,04-1,96 при CI 95\%) для передбачення несприятливих ЗПР при материнському ЦД. RR розвитку респіраторного дистрес-синдрому (РДС) після народження при різних антенатальних ехографічних і допплеровских особливостях знаходився в діапазоні від 0,5 до 1,46 при 95\% CI.

Висновки. Результати антенатальних Уз моніторингів при ЦД строго залежать від типу глікемічного контролю. Антенатальні ехографічні моніторинги є ефективними в діагностиці діабетичної фетопатії та передбаченні перинатального результату, але не є ефективними в прогнозуванні функціональної зрілості легенів і розвитку РДС у новонароджених від матерів з ЦД.

Ключові слова: вагітність, цукровий діабет, ультразвуковий моніторинг, діабетична фетопатія, перинатальний результат. antenatal predictors as uncontrolled and suboptimally controlled glycemia, fetal growth retardation (FGR), UA and MCA Doppler changes had a strong relationship with adverse GPO (RR 9,53-2,9 95\% CI). So such US signs of placental dysfunction in DM as FGR and abnormal UA and/or MCA Doppler changes were important and universal predictors of high perinatal risk and adverse pregnancy outcome, although it was not a predictor of precisely diabetic fetopathy. RR of respiratory distress after birth in various antenatal and Doppler ultrasonographic features ranged from 0.5 to 1.46 with $95 \%$ CI.

Conclusions. The results of antenatal US monitoring in DM women are strictly dependent on the type of glycemic control. Antenatal US monitoring is effective in the diagnosis of diabetic fetopathy and prediction of perinatal outcome, but ineffective in predicting of the functional maturation of the lungs and the development of respiratory distress in newborns of mothers with DM.

Key words: pregnancy, diabetes mellitus, ultrasound monitoring, diabetic fetopathy, perinatal outcome. 